\title{
Calculated Entropies for $n$-Heptane, 2-Methylhexane, 2,3-Dimethylpentane, and Radicals from the Loss of H Atoms
}

\author{
Jason M. Hudzik and Joseph W. Bozzelli \\ Chemistry, Chemical Engineering and Environmental Science, New Jersey Institute of Technology, Newark, NJ 07102, USA \\ Correspondence should be addressed to Joseph W. Bozzelli; bozzelli@njit.edu
}

Received 14 March 2013; Revised 17 May 2013; Accepted 19 May 2013

Academic Editor: Miquel Solà

Copyright ( 2013 J. M. Hudzik and J. W. Bozzelli. This is an open access article distributed under the Creative Commons Attribution License, which permits unrestricted use, distribution, and reproduction in any medium, provided the original work is properly cited.

\begin{abstract}
Entropy data are reported using different calculation methods for internal rotors on $n$-heptane, 2-methylhexane, and 2,3dimethylpentane and on the different radical sites of each species corresponding to the loss of a hydrogen atom for temperatures between 298 and $1500 \mathrm{~K}$. Structures, moments of inertia, vibration frequencies, and internal rotor potentials are calculated at the B3LYP/6-31G(d,p) level of theory. Comparisons with experimental literature data suggest limitations inuse of the rigid-rotor harmonic-oscillator $(\mathrm{HO})$ approximation and advantages to the use of internal rotation contributions for entropy relative to torsion frequencies. The comparisons suggest the need to include contributions from all internal rotors where the barriers are at or below those of the above molecules. Calculation of entropy from the use of internal rotor contributions provides acceptable approximations to available literature values. Entropy values for radicals corresponding to carbon sites on these hydrocarbons are presented.
\end{abstract}

\section{Introduction}

Over the past decades advancements made in quantum chemistry, including the evolution of density functional theory (DFT) and compound methods, coupled with increasing computer processing power, have allowed for substantial advancements in estimating thermochemical and other chemical properties and systems [1].

Thermochemical properties including enthalpies, entropies, and heat capacities for stable molecules and for radicals corresponding to the loss of $\mathrm{H}$ atom through abstraction reactions are important and necessary for building and analyzing detailed chemical kinetic models. Several research studies have focused on linear and branched alkanes, including $n$ heptane, [2-6] because it has been considered as an important surrogate for major components in diesel and spark ignition transportation fuels. The parent hydrocarbons might be stable alkanes that have been studied experimentally, but oxidation under both atmospheric and combustion conditions creates hundreds of intermediate species that are fragmented, partially oxygenated, and/or unsaturated. The stability, thermochemical properties, and chemical kinetics of these intermediates is needed for the model used for optimization.

Enthalpy, entropy, and heat capacity are all important because of the influence they have on reactions' paths. The $\mathrm{T} \Delta \mathrm{S}$ entropy term in the Gibbs Energy influences the equilibrium constant and calculation of reverse reaction rate constants with a large lever because of the temperature multiplier. Entropy also has a large contribution to preexponential factors. The advances in high level computational methods have resulted in accurate determination of thermochemical properties for linear and branched alkanes [7-9].

When determining the standard enthalpy of formation for a species, for example, it is common to implement different theoretical chemical equations that incorporate mass balance, with equivalent hybridization, and bond type on each side of a work equation. This allows for significant error cancellation via the use of a $\Delta \mathrm{H}_{\text {reaction }}$ due to similar environments, which result in the cancelation of error resulting, on both sides of the reaction equation. Hierarchies of the reaction classes have been created allowing for a better idea of the error cancelling provided [10]. Employing these techniques also allows lower level and less computationally 


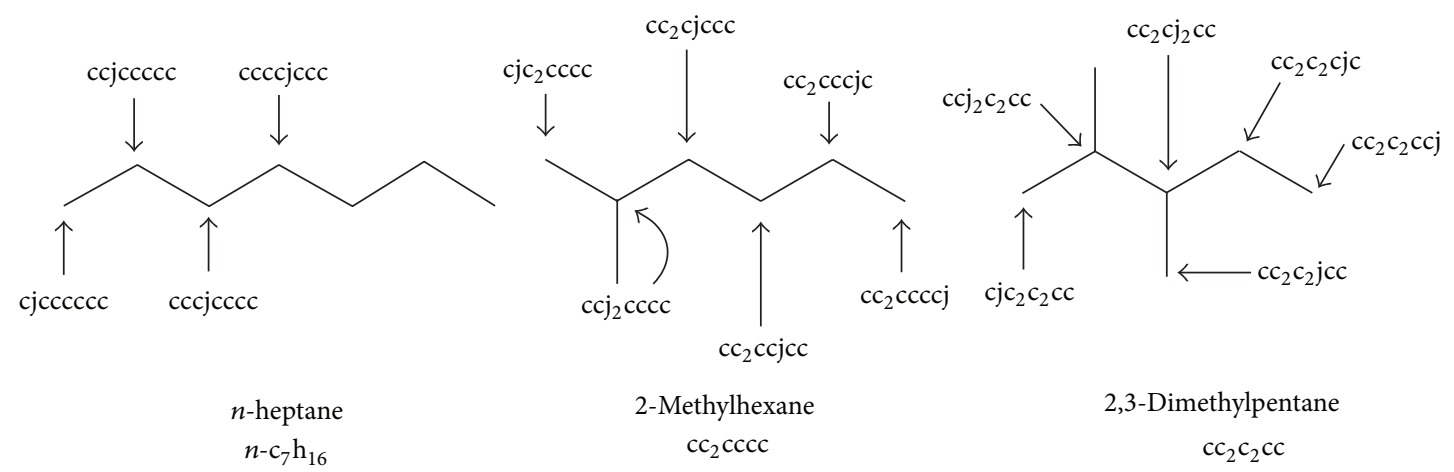

Figure 1: Parent and radical $\mathrm{C}_{7} \mathrm{H}_{16}$ species in this study.

demanding methods to be used without sacrificing the accuracy.

For entropy and heat capacity calculations, the simple rigid-rotor harmonic-oscillator $(\mathrm{HO})$ is utilized, almost exclusively, to describe the $3 \mathrm{~N}-6$ vibrations for nonlinear species and the corresponding contributions to entropy and heat capacities. It is well known that there are accuracy issues in determining the lower frequency torsions corresponding to internal rotations using this approximation. This can be corrected by replacing these frequencies with methods to treat the internal rotations as hindered rotors to increase accuracy for thermodynamic properties and reaction kinetics [12-17].

The initial research papers of Pitzer and Gwinn [18-20] addressed contributions from symmetrical and unsymmetrical rotating groups on a rigid frame. Later work by Kilpatrick and Pitzer [21] expanded the method to include balanced and unbalanced linked rotating groups. These studies still serve as a basis for current research and development for new methods for treating internal rotations.

A number of studies utilizing different techniques for handling coupled and uncoupled internal rotor contributions have been reported $[12,13,16,22-26]$. Although more advanced methods addressing coupled internal rotators are available, basic treatment of internal rotations as uncoupled rotations provides improved accuracy over the $\mathrm{HO}$ approximation alone $[22,24,27]$. This has been shown through comparisons between experimental and computational entropies and heat capacities of $n$-alkanes [22, 26-28].

The goal of the present study is to calculate entropy values for $n$-heptane, 2-methylhexane, and 2,3-dimethylpentane, compare them to available literature data, and then use the method(s) which appear to be optimal, to calculate entropy data for their carbon-centered radicals shown in Figure 1. String nomenclatures of the radical species are written with the letter $\mathrm{j}$ representing a radical site on the preceding carbon atom. Values from several calculation methods used to account for internal rotation contribution to entropy were compared to available literature values. We also show comparisons of the entropy when only the torsion frequency contributions from the methyl rotors are replaced by contributions from internal rotor analysis and torsion frequency contributions from other rotors is continued.

\section{Computational Methods}

The parent and radical species were optimized at the B3LYP $[30,31]$ level of theory with the $6-31 G(d, p)$ basis set using the Gaussian 03 program suite [32]. Potential energy curves for all single bond rotations were determined for each species using scans at $10^{\circ}$ intervals. During the rotation, the geometry was allowed to relax. The scans also serve to verify that our optimized structures were the lowest energy geometries. If there was a lower energy structure, species were reoptimized and scans were rerun to verify that we were working with the lowest energy structures. We note that the relaxed scan may not accurately represent the actual rotation motion for all rotors, as the vibration motion does not necessarily adjust to compensate for internal rotations.

\section{Calculation Methods}

The three methods that we will use in our entropy analysis are given below.

3.1. SMCPS. Translations, vibrations, and external rotation (denoted TVR) contributions to entropy are determined using the Statistical Mechanics for Heat Capacity and Entropy (SMCPS) program [33]. The SMCPS program applies the rigid-rotor harmonic-oscillator $(\mathrm{HO})$ approximation using the geometry, frequencies, and moments of inertia from the optimized B3LYP/6-31G(d,p) structure along with the mass, electronic degeneracy, symmetry, and number of optical isomers for each species. The zero-point vibration energies (ZPVE) are scaled by 0.9806 as recommended by Scott and Radom [34]. Other than the frequency scaling factor this is used without corrections.

This code is also used for the vibrations with corresponding torsion frequencies removed in the VIBIR and ROTATOR calculation for the internal rotor contributions below.

3.2. VIBIR. This method will analyze internal rotation contributions to entropy with the Pitzer and Gwinn [18-20] approximation method as applied in the VIBIR [35] code. The barriers and foldness of the potential energy graphs for each bond rotation are used; there is no adjustment for coupling of internal rotor motion with vibration. The reduced moments of inertia were calculated based on the optimized 
TABLE 1: Comparison of calculated entropies for $\mathrm{C}_{7} \mathrm{H}_{16}$ parent species to available literature values.

\begin{tabular}{|c|c|c|c|c|c|c|c|c|}
\hline \multirow{2}{*}{ Species } & \multicolumn{7}{|c|}{$S^{\circ}(T)\left(\mathrm{cal} \mathrm{mol}^{-1} \mathrm{~K}^{-1}\right)$} & \multirow{2}{*}{ Method } \\
\hline & $298 \mathrm{~K}$ & $400 \mathrm{~K}$ & $500 \mathrm{~K}$ & $600 \mathrm{~K}$ & $800 \mathrm{~K}$ & $1000 \mathrm{~K}$ & $1500 \mathrm{~K}$ & \\
\hline \multirow{7}{*}{$n-c_{7} h_{16}$} & 95.43 & 107.58 & 119.24 & 130.57 & 151.90 & 171.31 & 212.40 & SMCPS (1) \\
\hline & 90.46 & 102.14 & 113.40 & 124.36 & 144.96 & 163.73 & 203.47 & SMCPS/Methyl (18) \\
\hline & 101.58 & 112.39 & 123.07 & 133.56 & 153.39 & 171.42 & 209.33 & SMCPS/VIBIR (18) \\
\hline & 105.05 & 117.98 & 129.96 & 141.33 & 162.34 & 181.21 & 220.80 & SMCPS/ROTATOR (18) \\
\hline & 102.27 & 115.46 & 127.77 & 139.47 & 161.01 & 180.29 & & {$[29]$} \\
\hline & 102.29 & 115.41 & 127.72 & 139.5 & 161.2 & 180.5 & 220.5 & {$[11]$} \\
\hline & 102.78 & 116.09 & 128.46 & 140.18 & 161.73 & 180.99 & 221.20 & {$[28]$} \\
\hline \multirow{7}{*}{$\mathrm{CC}_{2} \mathrm{Cccc}$} & 94.95 & 107.28 & 119.07 & 130.48 & 151.89 & 171.35 & 212.48 & SMCPS (1) \\
\hline & 90.10 & 101.73 & 112.94 & 123.81 & 144.19 & 162.69 & 201.82 & SMCPS/Methyl (27) \\
\hline & 100.14 & 111.16 & 121.93 & 132.46 & 152.26 & 170.22 & 208.03 & SMCPS/VIBIR (27) \\
\hline & 103.70 & 116.75 & 128.87 & 140.37 & 161.54 & 180.50 & 220.20 & SMCPS/ROTATOR (27) \\
\hline & 100.38 & 113.57 & 125.88 & 137.58 & 159.12 & 178.40 & & {$[29]$} \\
\hline & 100.48 & 113.63 & 126.03 & 137.9 & 159.7 & 179.3 & 220.0 & {$[11]$} \\
\hline & 101.33 & 114.71 & 127.13 & 138.89 & 160.48 & 179.75 & 219.96 & {$[28]$} \\
\hline \multirow{6}{*}{$\mathrm{Cc}_{2} \mathrm{c}_{2} \mathrm{cc}$} & 94.72 & 107.21 & 119.10 & 130.58 & 152.06 & 171.54 & 212.67 & SMCPS (1) \\
\hline & 91.55 & 103.14 & 114.21 & 124.91 & 144.89 & 163.02 & 201.42 & SMCPS/Methyl (81) \\
\hline & 98.61 & 109.77 & 120.54 & 131.01 & 150.63 & 168.46 & 206.10 & SMCPS/VIBIR (81) \\
\hline & 99.44 & 112.53 & 124.65 & 136.13 & 157.27 & 176.20 & 215.84 & SMCPS/ROTATOR (81) \\
\hline & 98.96 & 112.15 & 124.46 & 136.16 & 157.70 & 176.98 & & {$[29]$} \\
\hline & 99.08 & 112.09 & 124.5 & 136.3 & 158.3 & 177.9 & 219.3 & {$[11]$} \\
\hline
\end{tabular}

Subtracted $0.026 \mathrm{cal} \mathrm{mol}^{-1} \mathrm{~K}^{-1}$ from values in Reference [28] to convert from a standard pressure of $1 \mathrm{bar}$ to $1 \mathrm{~atm}$. Symmetry values are given in parenthesis for our methods.

geometries using the mass and radius of rotation for the rotational groups.

VIBIR assumes that the rotational groups are symmetrical which is accurate for the primary and terminal methyl group rotation in these isomers. We also report results using VIBIR for nonsymmetrical internal rotors for comparison purposes.

3.3. ROTATOR. The second method for internal rotation treatment is with the ROTATOR [36] code. This uses the potential energy curves with expansion of the hindrance potential at discrete torsion angles in the truncated Fourier series:

$$
\begin{array}{r}
V(\varphi)=a_{0}+\sum a_{i} \cos (i \varphi)+\sum b_{i} \sin (i \varphi), \\
\text { where } i=1-7,
\end{array}
$$

where $a_{0}, a_{i}$, and $b_{i}$ provide the minima and maxima of the torsion potentials with the allowance for a shift of the theoretical extreme angular positions. It calculates the Hamiltonian matrix on the basis of 1-dimensional wave functions of free internal rotor with subsequent calculation of energy levels by direct diagonalization of the Hamiltonian matrix. The code also calculates the moments of inertia by methods recommended by Pitzer and Gwinn. By calculating all the energy levels of the internal rotor within the potential barriers, the analysis also incorporates contributions from optical isomers such as those of peroxides.

This method allows for a more accurate description of the internal rotor potential in the calculation of energy levels.
Both symmetrical and unsymmetrical barriers can be accurately described for calculated contributions to entropies and heat capacities.

\section{Results and Discussion}

4.1. Entropies $\left(S^{\circ}(T)\right)$ of Parent Species. The calculation sets used to calculate entropy contributions in this study can be grouped into four methods. Abbreviations for these methods are denoted in italics below and used in Table 1 and Figure 2. Symmetry corrections are denoted in Table 1 for each method as well as in the Supplementary Materials.

(i) SMCPS applies only the HO approximation. (There is no correction (subtraction) of $R \ln (\sigma)$ for the threefold symmetry of the primary methyl groups using the torsion frequencies, as there is in the use of Group Additivity.)

(ii) SMCPS/Methyl applies the HO approximation for all vibrations except methyl torsions, which are substituted with values from VIBIR, which shows similar values to ROTATOR for the methyl rotors.

(iii) SMCPS/VIBIR applies the $\mathrm{HO}$ approximation for vibrations with all torsion frequencies removed from SMCPS and replaced with contributions for internal rotors from use of VIBIR.

(iv) SMCPS/ROTATOR applies the HO approximation for vibrations with all torsion frequencies removed from SMCPS and replaced with contributions for internal rotors from the use of ROTATOR. 

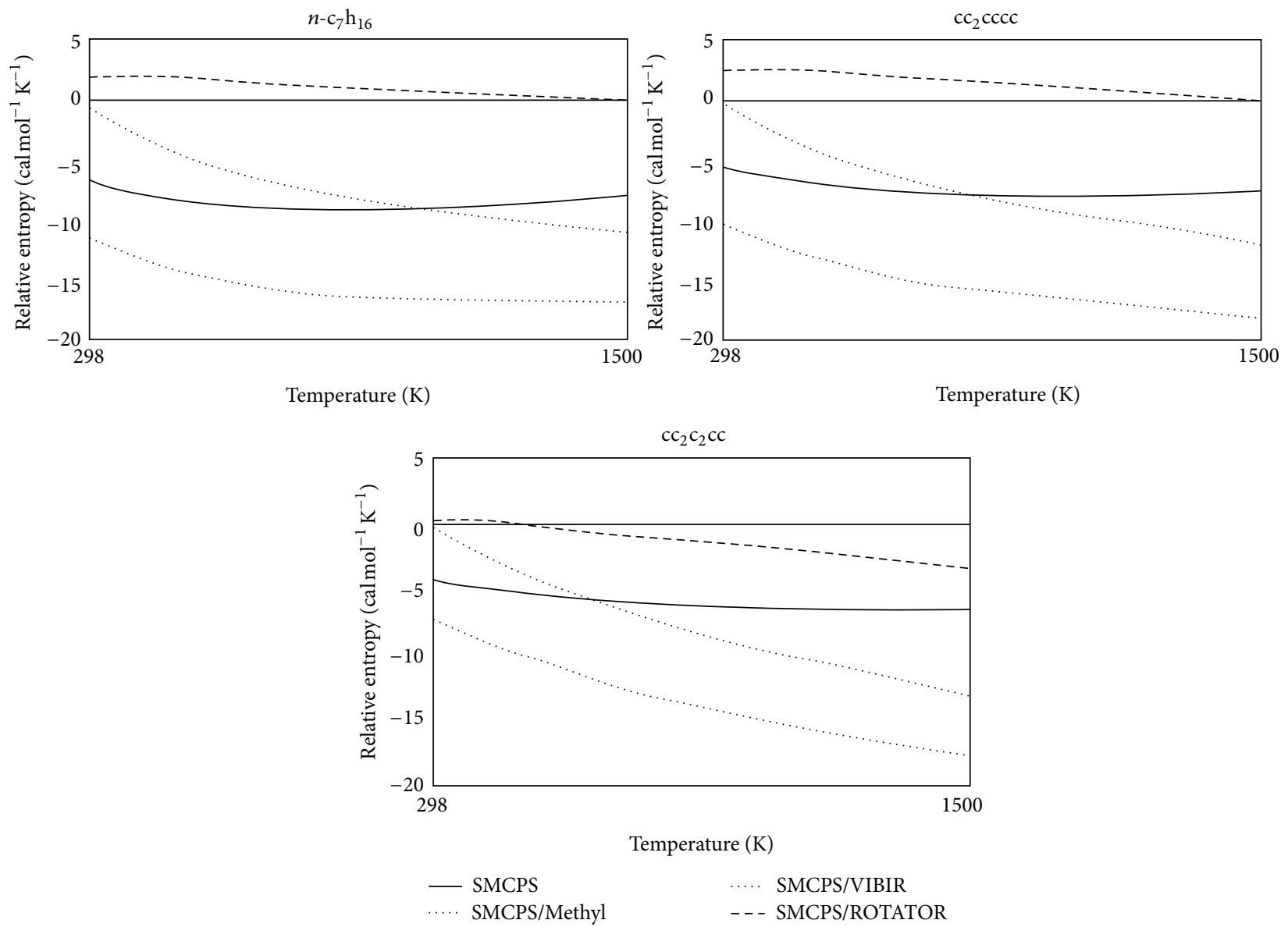

FIGURE 2: Comparison of our calculated entropies with the literature values [11].

Table 1 has a comparison between our calculated entropies with data from available reference literature values for the three stable hydrocarbons; this comparison provides a gauge on the methods. To determine the overall performance of the different methods, we calculated the relative difference in the entropies between $298-1500 \mathrm{~K}$ based on the literature values from Scott [11]. This is presented graphically in Figure 2.

The data in Table 1 for the parent molecules by the HO approximation method as implemented in the SMCPS code is shown to consistently underpredict entropies by $4-$ $9 \mathrm{cal} \mathrm{mol}^{-1} \mathrm{~K}^{-1}$ in this $298-1500 \mathrm{~K}$ temperature range. It is noted that as the branching of these isomers increases, the $\mathrm{HO}$ approximation shows an increase in accuracy. Overall as the temperature increases we observe a growing deviation.

In a second analysis, each of the parent alkanes analyzed has the terminal methyl rotation contributions from the use of the Pitzer and Gwinn approximation method in the VIBIR code. These symmetrical terminal methyl rotations should be accurately calculated using this method. The contributions from the torsion frequencies associated with terminal methyl rotations are replaced with the VIBIR values and they are incorporated with the remaining vibration contributions at each temperature.

These SMCPS/Methyl values, in Figure 2, are observed to significantly underestimate the entropies by 7$12 \mathrm{cal} \mathrm{mol}^{-1} \mathrm{~K}^{-1}$ at $298 \mathrm{~K}$ and $17-18 \mathrm{cal} \mathrm{mol}^{-1} \mathrm{~K}^{-1}$ at $1500 \mathrm{~K}$ compared to the Scott values. In this case, it would be a better estimate to use the HO approximation values from SMCPS than to only consider the methyl rotations.

Calculation of entropy contributions using all of the internal rotors, which are considered to be uncoupled, was performed using both VIBIR and ROTATOR. Determining the corresponding rotation-vibration torsions using visualization in GaussView 5 was problematic due to the coupling of several internal rotors. To evaluate this, we tested several different vibration pair combinations where frequency evaluation in GaussView indicated torsions. It was observed that there was an insignificant change in the entropies using the various combinations. Internal rotations are typically characterized by lower vibrational frequencies as compared to other motions, so to maintain consistency the first six vibration frequencies for each species were replaced with the data from the respective rotor method. The data on these trials is included in the Supplementary Materials available online at http://dx.doi.org/10.1155/2013/673065.

At $298 \mathrm{~K}$, the SMCPS/VIBIR values provide accuracy within $1 \mathrm{cal} \mathrm{mol}^{-1} \mathrm{~K}^{-1}$ to the reference values for all of the parent species; SMCPS/ROTATOR provides a slightly closer value for $\mathrm{Cc}_{2} \mathrm{c}_{2} \mathrm{cc}$. As the temperature increases, the SMCPS/VIBIR values trend to underestimate the Scott values by up to $11-13 \mathrm{cal} \mathrm{mol}^{-1} \mathrm{~K}^{-1}$ at $1500 \mathrm{~K}$. In contrast, SMCPS/ROTATOR provides a much closer approximation 
TABLE 2: Comparison of calculated entropies for $\mathrm{C}_{7} \mathrm{H}_{16}$ radical species.

\begin{tabular}{|c|c|c|c|c|c|c|c|}
\hline \multirow{2}{*}{ Species } & \multicolumn{7}{|c|}{$S^{\circ}(T)\left(\mathrm{cal} \mathrm{mol}^{-1} \mathrm{~K}^{-1}\right)$} \\
\hline & $298 \mathrm{~K}$ & $400 \mathrm{~K}$ & $500 \mathrm{~K}$ & $600 \mathrm{~K}$ & $800 \mathrm{~K}$ & $1000 \mathrm{~K}$ & $1500 \mathrm{~K}$ \\
\hline \multirow{2}{*}{$\operatorname{cjcccccc}(3)$} & 106.41 & 117.09 & 127.56 & 137.78 & 156.96 & 174.30 & 210.56 \\
\hline & 111.59 & 124.23 & 135.91 & 146.99 & 167.34 & 185.53 & 223.52 \\
\hline \multirow{2}{*}{$\operatorname{ccjccccc}(9)$} & 106.14 & 116.68 & 126.95 & 136.97 & 155.82 & 172.92 & 208.88 \\
\hline & 111.06 & 123.37 & 134.81 & 145.70 & 165.82 & 183.88 & 221.72 \\
\hline \multirow{2}{*}{$\operatorname{cccjcccc}(9)$} & 106.55 & 117.35 & 127.71 & 137.75 & 156.53 & 173.54 & 209.33 \\
\hline & 111.44 & 123.64 & 135.05 & 145.92 & 166.01 & 184.05 & 221.87 \\
\hline \multirow{2}{*}{$\operatorname{ccccjccc}(9)$} & 106.57 & 117.39 & 127.76 & 137.81 & 156.58 & 173.58 & 209.34 \\
\hline & 110.88 & 123.28 & 134.81 & 145.77 & 165.95 & 184.04 & 221.90 \\
\hline \multirow{2}{*}{$\operatorname{cjc}_{2} \operatorname{cccc}(9)$} & 105.12 & 116.02 & 126.60 & 136.86 & 156.03 & 173.31 & 209.45 \\
\hline & 107.08 & 120.13 & 132.07 & 143.30 & 163.83 & 182.10 & 220.15 \\
\hline \multirow{2}{*}{$\operatorname{ccj}_{2} \operatorname{cccc}(54)$} & 103.43 & 113.75 & 123.76 & 133.55 & 152.04 & 168.88 & 204.51 \\
\hline & 106.93 & 118.99 & 130.23 & 140.95 & 160.84 & 178.75 & 216.42 \\
\hline \multirow{2}{*}{$\mathrm{cc}_{2} \operatorname{cjccc}(27)$} & 103.94 & 114.91 & 125.37 & 135.44 & 154.20 & 171.13 & 206.77 \\
\hline & 106.72 & 119.40 & 131.11 & 142.17 & 162.47 & 180.60 & 218.48 \\
\hline \multirow{2}{*}{$\mathrm{cc}_{2} \operatorname{ccjcc}(27)$} & 102.28 & 113.40 & 124.04 & 134.28 & 153.30 & 170.42 & 206.31 \\
\hline & 105.78 & 118.51 & 130.29 & 141.42 & 161.83 & 180.05 & 218.06 \\
\hline \multirow{2}{*}{$\mathrm{cc}_{2} \operatorname{cccjc}(27)$} & 103.36 & 114.13 & 124.51 & 134.58 & 153.41 & 170.46 & 206.31 \\
\hline & 106.40 & 119.07 & 130.75 & 141.80 & 162.10 & 180.26 & 218.20 \\
\hline \multirow{2}{*}{$\mathrm{cc}_{2} \operatorname{ccccj}(9)$} & 103.60 & 114.48 & 125.04 & 135.28 & 154.44 & 171.71 & 207.88 \\
\hline & 107.25 & 120.04 & 131.87 & 143.05 & 163.55 & 181.82 & 219.90 \\
\hline \multirow{2}{*}{$\mathrm{cjc}_{2} \mathrm{c}_{2} \mathrm{cc}(27)$} & 102.45 & 113.64 & 124.28 & 134.53 & 153.59 & 170.79 & 206.91 \\
\hline & 102.42 & 115.48 & 127.48 & 138.77 & 159.39 & 177.72 & 215.86 \\
\hline \multirow{2}{*}{$\mathrm{ccj}_{2} \mathrm{c}_{2} \mathrm{cc}(81)$} & 102.41 & 113.00 & 123.25 & 133.19 & 151.82 & 168.72 & 204.36 \\
\hline & 103.60 & 115.88 & 127.29 & 138.14 & 158.18 & 176.18 & 213.94 \\
\hline \multirow{2}{*}{$\mathrm{cc}_{2} \mathrm{cj}_{2} \mathrm{cc}(81)$} & 102.01 & 112.63 & 122.80 & 132.62 & 151.00 & 167.67 & 202.97 \\
\hline & 103.90 & 116.05 & 127.38 & 138.19 & 158.15 & 176.08 & 213.73 \\
\hline \multirow{2}{*}{$\mathrm{Cc}_{2} \mathrm{c}_{2} \mathrm{j} \mathrm{cc}$ (27) } & 101.47 & 112.59 & 123.24 & 133.50 & 152.62 & 169.86 & 206.01 \\
\hline & 102.16 & 115.33 & 127.38 & 138.69 & 159.33 & 177.66 & 215.80 \\
\hline \multirow{2}{*}{$\mathrm{Cc}_{2} \mathrm{c}_{2} \mathrm{cjc}(81)$} & 100.32 & 111.32 & 121.90 & 132.10 & 151.07 & 168.18 & 204.10 \\
\hline & 100.27 & 113.36 & 125.38 & 136.67 & 157.25 & 175.55 & 213.63 \\
\hline \multirow{2}{*}{$\mathrm{cc}_{2} \mathrm{c}_{2} \mathrm{ccj}(27)$} & 101.71 & 112.87 & 123.53 & 133.78 & 152.84 & 170.03 & 206.08 \\
\hline & 102.51 & 115.67 & 127.69 & 138.97 & 159.53 & 177.82 & 215.88 \\
\hline
\end{tabular}

Values are from SMCPS/VIBIR and SMCPS/ROTATOR (in bold). Symmetry values are given in parenthesis for our methods.

throughout the temperature range. This suggests that modeling all of the rotors, where the rotational barriers are similar or lower to those determined for these hydrocarbon parents and radicals results in a better approximation to entropy.

The HO approximation with corrections for internal rotations by the ROTATOR code provided the best comparison to the available literature reference values. It is important to note that SMCPS/VIBIR provides very good values at $298 \mathrm{~K}$.

4.2. Entropies $\left(S^{\circ}(T)\right)$ of Radical Species. Entropies using the SMCPS/ROTATOR and SMCPS/VIBIR methods for the radical species are shown in Table 2. The SMCPS/ROTATOR values are given in bold, and it is seen that the SMCPS/VIBIR values are lower in comparison with an increasing deviation with increasing temperature.

SMCPS/VIBIR provides acceptable agreement with the SMCPS/ROTATOR values at $298 \mathrm{~K}$ as it did for the parent species. There is approximately a $2 \mathrm{cal} \mathrm{mol}^{-1} \mathrm{~K}^{-1}$ difference for $\operatorname{cjc}_{2} \operatorname{cccc}$ while the 2,3-dimethylpentane radicals all fall below a $1 \mathrm{cal} \mathrm{mol}^{-1} \mathrm{~K}^{-1}$ difference. This is not the case at higher temperatures, however, as the deviation increases with a minimum difference of $9 \mathrm{cal} \mathrm{mol}^{-1} \mathrm{~K}^{-1}$ at $1500 \mathrm{~K}$ between the two methods. VIBIR is based on the symmetrical barriers, while ROTATOR accurately models the complete potential energy curves for the internal rotation. In the SMCPS/VIBIR method all of the internal rotations which include asymmetrical nonmethyl rotations utilize the average barrier heights for the rotors. The error created by this approximation is not as pronounced at lower temperatures but is apparent in the larger deviation at increased temperatures. We attribute these differences to our use of the Pitzer and Gwinn method in our VIBIR code not being able to account for the nonsymmetrical internal rotor barriers, where the ROTATOR method does fully account for wells in nonsymmetrical barriers. 
Since literature values are not available for the entropy of the radicals, our recommendation is to use the SMCPS/ ROTATOR values in Table 2; this is based on the calculated results for the parent species.

\section{Summary}

Internal rotational barriers, moments of inertia, and vibrational frequencies were determined at the B3LYP/6-31G(d,p) level of theory for rotor contribution analysis. These potentials were used to determine entropies from 298 to $1500 \mathrm{~K}$ for $n$-heptane, 2-methylhexane, 2,3-dimethylpentane, and their radicals using torsion frequencies, Pitzer and Gwinn's analysis, and a Schrodinger equation solution method. The $\mathrm{HO}$ approximation-torsion frequency calculation consistently underestimated the entropies compared to reference literature values. Values calculated which were only adjusted for terminal methyl rotations were substantially worse compared to the $\mathrm{HO}$ values, especially at increased temperatures. The HO approximation values which used internal rotational contributions from the ROTATOR code provided the best analysis over the 298-1500 K temperature range.

Entropies calculated using the SMCPS/ROTATOR method is recommended for the radical species. We plan on extending this analysis to include enthalpies, heat capacities, and bond dissociation energies in a future publication.

\section{References}

[1] S. F. Sousa, P. A. Fernandes, and M. J. Ramos, "General performance of density functionals," The Journal of Physical Chemistry A, vol. 111, no. 42, pp. 10439-10452, 2007.

[2] H. J. Curran, P. Gaffuri, W. J. Pitz, and C. K. Westbrook, "A comprehensive modeling study of $n$-heptane oxidation," Combustion and Flame, vol. 114, no. 1-2, pp. 149-177, 1998.

[3] H. J. Curran, W. J. Pitz, C. K. Westbrook, C. V. Callahan, and F. L. Dryer, "Oxidation of automotive primary reference fuels at elevated pressures," Symposium (International) on Combustion, vol. 27, no. 1, pp. 379-387, 1998.

[4] T. J. Held, A. J. Marchese, and F. L. Dryer, "A semi-empirical reaction mechanism for $n$-heptane oxidation and pyrolysis," Combustion Science and Technology, vol. 123, no. 1-6, pp. 107146, 1997.

[5] K. K. Pant and D. Kunzru, "Pyrolysis of $n$-heptane: kinetics and modeling," Journal of Analytical and Applied Pyrolysis, vol. 36, no. 2, pp. 103-120, 1996.

[6] T. Yuan, L. Zhang, Z. Zhou, M. Xie, L. Ye, and F. Qi, "Pyrolysis of $n$-heptane: experimental and theoretical study," The Journal of Physical Chemistry A, vol. 115, no. 9, pp. 1593-1601, 2011.

[7] J. Zheng, T. Yu, and D. G. Truhlar, "Multi-structural thermodynamics of $\mathrm{C}-\mathrm{H}$ bond dissociation in hexane and isohexane yielding seven isomeric hexyl radicals," Physical Chemistry Chemical Physics, vol. 13, no. 43, pp. 19318-19324, 2011.

[8] A. Karton, D. Gruzman, and J. M. L. Martin, "Benchmark thermochemistry of the $\mathrm{C}_{n} \mathrm{H}_{2 n+2}$ alkane isomers $(n=2-8)$ and performance of DFT and composite $A b$ initio methods for dispersion-driven isomeric equilibria," The Journal of Physical Chemistry A, vol. 113, no. 29, pp. 8434-8447, 2009.

[9] D. Gruzman, A. Karton, and J. M. L. Martin, "Performance of $A b$ initio and density functional methods for conformational equilibria of $\mathrm{C}_{n} \mathrm{H}_{2 n+2}$ alkane isomers $n=4-8$," The Journal of Physical Chemistry A, vol. 113, no. 43, pp. 11974-11983, 2009.

[10] S. E. Wheeler, K. N. Houk, P. V. R. Schleyer, and W. D. Allen, "A hierarchy of homodesmotic reactions for thermochemistry," Journal of the American Chemical Society, vol. 131, no. 7, pp. 2547-2560, 2009.

[11] D. W. Scott, Chemical Thermodynamic Properties of Hydrocarbons and Related Substances. Properties of the Alkane Hydrocarbons, C1 through C10 in the Ideal Gas State from 0 to 1500 K., U.S. Bureau of Mines, Bulletin 666, 1974.

[12] J. Pfaendtner, X. Yu, and L. J. Broadbelt, “The 1-D hindered rotor approximation," Theoretical Chemistry Accounts, vol. 118, no. 56, pp. 881-898, 2007.

[13] V. van Speybroeck, D. van Neck, M. Waroquier, S. Wauters, M. Saeys, and G. B. Marin, "Ab initio study of radical addition reactions: addition of a primary ethylbenzene radical to ethene (I)," The Journal of Physical Chemistry A, vol. 104, no. 46, pp. 10939-10950, 2000.

[14] V. van Speybroeck, Y. Borremans, D. van Neck et al., " $A b$ initio study of radical reactions: cyclization pathways for the butylbenzene radical (II)," The Journal of Physical Chemistry A, vol. 105, no. 32, pp. 7713-7723, 2001.

[15] V. van Speybroeck, D. van Neck, and M. Waroquier, “Ab initio study of radical reactions: role of coupled internal rotations on the reaction kinetics (III)," The Journal of Physical Chemistry A, vol. 106, no. 38, pp. 8945-8950, 2002.

[16] S. Sharma, S. Ramans, and W. H. Green, "Intramolecular hydrogen migration in alkylperoxy and hydroperoxyalkylperoxy radicals: accurate treatment of hindered rotors," The Journal of Physical Chemistry A, vol. 114, no. 18, pp. 5689-5701, 2010.

[17] G. Reinisch, J. M. Leyssale, and G. L. Vignoles, "Hindered rotor models with variable kinetic functions for accurate thermodynamic and kinetic predictions," The Journal of Chemical Physics, vol. 133, no. 15, Article ID 154112, 10 pages, 2010.

[18] K. S. Pitzer, "Thermodynamic functions for molecules having restricted internal rotations," The Journal of Chemical Physics, vol. 5, no. 6, pp. 469-472, 1937.

[19] K. S. Pitzer, "Energy levels and thermodynamic functions for molecules with internal rotation: II. Unsymmetrical tops attached to a rigid frame," Journal of Chemical Physics, vol. 14, no. 4, pp. 239-243, 1946.

[20] K. S. Pitzer and W. D. Gwinn, "Energy levels and thermodynamic functions for molecules with internal rotation: I. Rigid frame with attached tops," The Journal of Chemical Physics, vol. 10, no. 7, pp. 428-440, 1942.

[21] J. E. Kilpatrick and K. S. Pitzer, "Energy levels and thermodynamic functions for molecules with internal rotation. III. Compound rotation," The Journal of Chemical Physics, vol. 17, no. 11, pp. 1064-1075, 1949.

[22] V. van Speybroeck, P. Vansteenkiste, D. van Neck, and M. Waroquier, "Why does the uncoupled hindered rotor model work well for the thermodynamics of n-alkanes?" Chemical Physics Letters, vol. 402, no. 4-6, pp. 479-484, 2005.

[23] P. Y. Ayala and H. B. Schlegel, "Identification and treatment of internal rotation in normal mode vibrational analysis," Journal of Chemical Physics, vol. 108, no. 6, pp. 2314-2325, 1998.

[24] P. Vansteenkiste, D. van Neck, V. van Speybroeck, and M. Waroquier, "An extended hindered-rotor model with incorporation of Coriolis and vibrational-rotational coupling for calculating partition functions and derived quantities," Journal of Chemical Physics, vol. 124, no. 4, Article ID 044314, 14 pages, 2006. 
[25] C. Y. Lin, E. I. Izgorodina, and M. L. Coote, "How accurate are approximate methods for evaluating partition functions for hindered internal rotations?" The Journal of Physical Chemistry A, vol. 112, no. 9, pp. 1956-1964, 2008.

[26] P. Vansteenkiste, V. van Speybroeck, E. Pauwels, and M. Waroquier, "How should we calculate multi-dimensional potential energy surfaces for an accurate reproduction of partition functions?" Chemical Physics, vol. 314, no. 1-3, pp. 109-117, 2005.

[27] P. Vansteenkiste, V. van Speybroeck, G. B. Marin, and M. Waroquier, "Ab initio calculation of entropy and heat capacity of gas-phase n-alkanes using internal rotations," The Journal of Physical Chemistry A, vol. 107, no. 17, pp. 3139-3145, 2003.

[28] T. Yu, J. Zheng, and D. G. Truhlar, "Statistical thermodynamics of the isomerization reaction between $n$-heptane and isoheptane," Physical Chemistry Chemical Physics, vol. 14, no. 2, pp. 482-494, 2012.

[29] D. R. Stull, E. F. Westrum Jr., and G. C. Sinke, The Chemical Thermodynamics of Organic Compounds, Wiley, New York, NY, USA, 1969.

[30] A. D. Becke, "Density-functional thermochemistry. III. The role of exact exchange," The Journal of Chemical Physics, vol. 98, no. 7, pp. 5648-5652, 1993.

[31] C. Lee, W. Yang, and R. G. Parr, "Development of the ColleSalvetti correlation-energy formula into a functional of the electron density," Physical Review B, vol. 37, no. 2, pp. 785-789, 1988.

[32] M. J. Frisch, G. W. Trucks, H. B. Schlegel et al., Gaussian 03, Revision D.01, Gaussian, Wallingford, Conn, USA, 2003.

[33] C. Sheng, Elementary, pressure dependent model for combustion of $\mathrm{Cl}, \mathrm{C} 2$ and nitrogen containing hydrocarbons: operation of a pilot scale incinerator and model comparison [Ph.D. dissertation], Department of Chemical Engineering, New Jersey Institute of Technology, Newark, NJ, USA, 2002.

[34] A. P. Scott and L. Radom, "Harmonic vibrational frequencies: an evaluation of Hartree-Fock, Møller-Plesset, quadratic configuration interaction, density functional theory, and semiempirical scale factors," The Journal of Physical Chemistry, vol. 100, no. 41, pp. 16502-16513, 1996.

[35] T. H. Lay, J. W. Bozzelli, A. M. Dean, and E. R. Ritter, "Hydrogen atom bond increments for calculation of thermodynamic properties of hydrocarbon radical species," The Journal of Physical Chemistry, vol. 99, no. 39, pp. 14514-14527, 1995.

[36] T. H. Lay, L. N. Krasnoperov, C. A. Venanzi, J. W. Bozzelli, and N. V. Shokhirev, "Ab initio study of $\alpha$-chlorinated ethyl hydroperoxides $\mathrm{CH}_{3} \mathrm{CH}_{2} \mathrm{OOH}, \mathrm{CH}_{3} \mathrm{CHClOOH}$, and $\mathrm{CH}_{3} \mathrm{CCl}_{2} \mathrm{OOH}$ : conformational analysis, internal rotation barriers, vibrational frequencies, and thermodynamic properties," The Journal of Physical Chemistry, vol. 100, no. 20, pp. 8240-8249, 1996. 

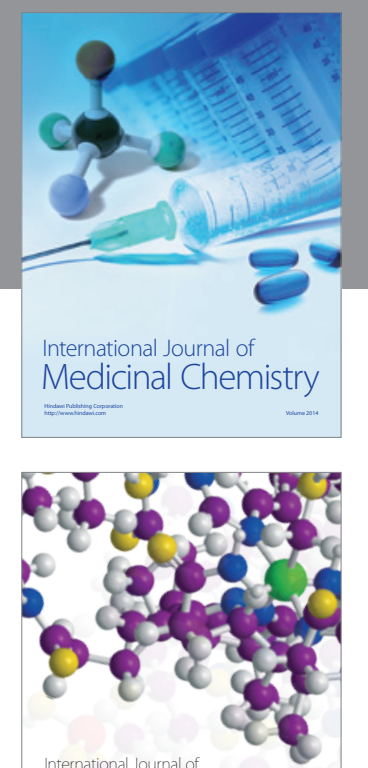

\section{Carbohydrate} Chemistry

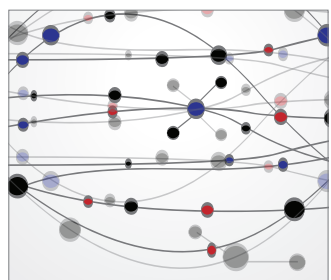

The Scientific World Journal
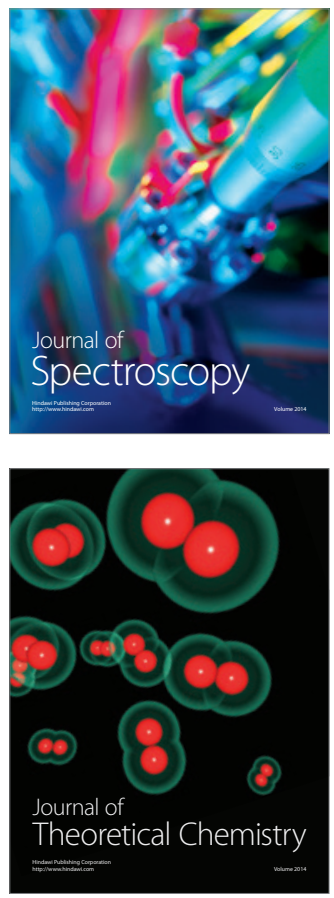
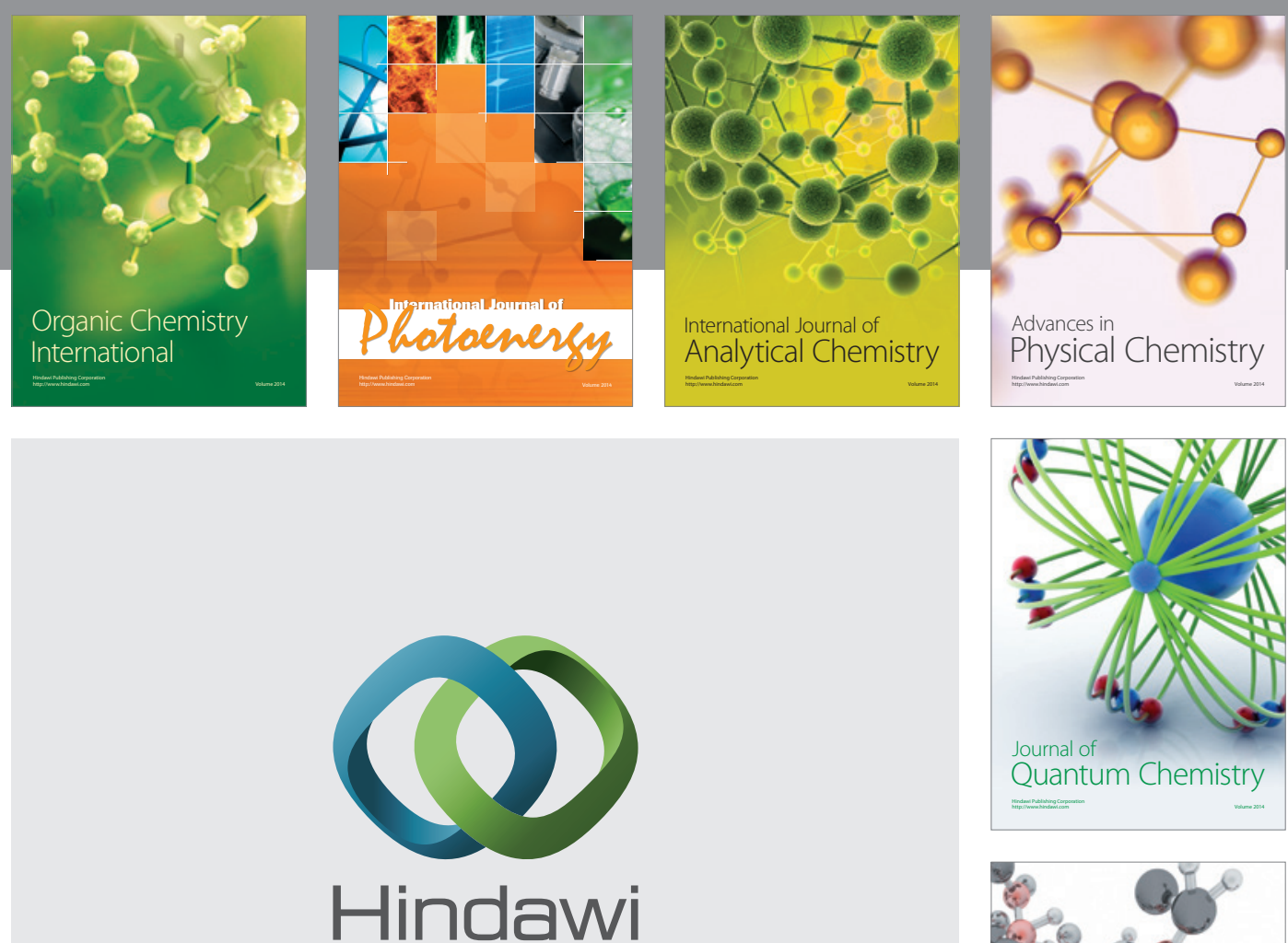

Submit your manuscripts at

http://www.hindawi.com

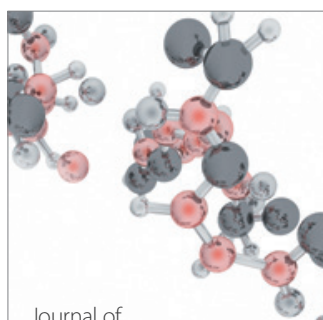

Analytical Methods

in Chemistry

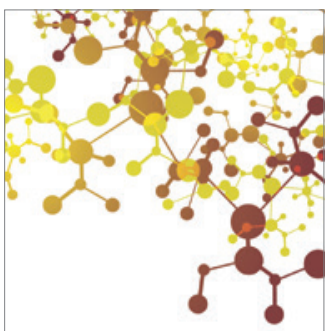

Journal of

Applied Chemistry

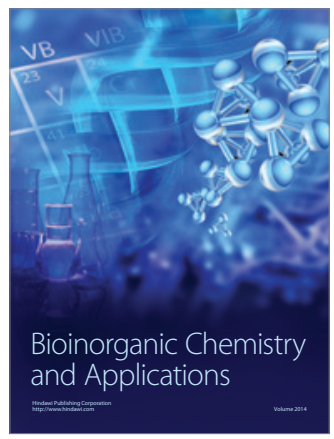

Inorganic Chemistry
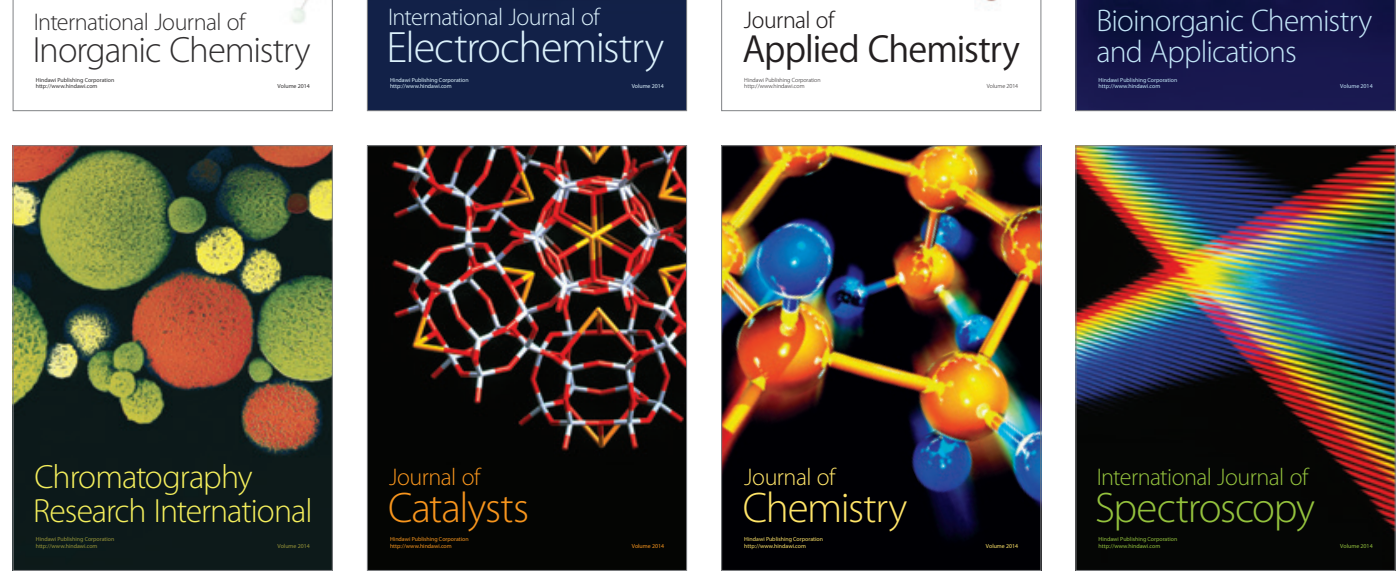